\title{
Probability Model for Human Fertility Behavior: Straddling Birth Interval Under Realistic Assumptions
}

\author{
Ajay Shankar Singh \\ Department of Agricultural Economics \& Management, University of Swaziland, Luyengo, Swaziland
}

\section{Email address:}

singhas64@hotmail.com (A. S. Singh), asingh@uniswa.sz (A. S. Singh)

\section{To cite this article:}

Ajay Shankar Singh. Probability Model for Human Fertility Behavior: Straddling Birth Interval Under Realistic Assumptions. American Journal of Theoretical and Applied Statistics. Vol. 4, No. 6, 2015, pp. 576-580. doi: 10.11648/j.ajtas.20150406.29

\begin{abstract}
Fertility analysis is important in understanding past, current and future trends of population size, Composition and growth. Information on fertility levels, patterns and trends experienced by a country is important for socio-economic planning, monitoring and evaluating programs. In recent years the study of birth intervals has acquired importance because of its relationships to fertility. The data on straddling birth interval, defined as a closed birth interval that straddles the survey date, is easy to obtain more accurately, though the collection of data requires retrospective as well as prospective surveys. This type of interval is useful for the study of reproduction of subsequent fecund women of a particular age group. In this paper, a probability distribution for the straddling birth interval regardless of parity has been derived by taking into account that different proportion of females are exposed to the risk of conception at different point of time. In this derived model, fecundability $(\lambda)$ has been considered to be constant over the study period. The duration of time from the point of termination of PPA to the state of exposure has been taken as random variable $(\mu)$ which follows exponential distribution. The maximum likelihood estimation technique has been used for the estimation of parameter $(\lambda) \&(\mu)$ through derived model.
\end{abstract}

Keywords: Probability Model, Fecundability, Birth Interval, Post Partum Amenorrhea (PPA), Contraceptive Practices

\section{Introduction}

Fertility is one of the components of population change as well as the positive force is responsible for the growth of human population. The researchers have given priority to understanding of the determinants of fertility through statistical methodologies. Fertility behavior is usually influenced by the action and interaction of a number of complex factors. It is now almost established that traditional socio-cultural practices which are a part of our social fabric have a very vital bearing on our social life and affect fertility variations in a complex manner. The social scientists and demographers have given high priority to thorough understanding of the differentials and determinants of fertility through various mathematical and statistical modeling techniques. Fertility behavior is usually influenced by the action and the interaction of a number of complex factors. Within the physiological limits of human reproduction, it is determined by a multiplicity if biosocial and demographic factors. The role of differentials in fertility has been reported by a number of researchers [1-3]. Mathematical models are very appropriate tools and are widely used for better understanding of the phenomenon of the complex process of human reproduction. In other words, these models are useful in understanding of the action and interaction or inter relationship among various factors as well as for predicting the change in fertility behavior. Mathematical models are very appropriate tools and widely used for better understanding of the complex human reproduction process.

The importance of differentials in fertility has been reported by a number of researchers and demographers [1-3]. Mathematical models are very appropriate tools and are widely used for better understanding of the phenomenon of the complex process of human fertility behavior. In other words, these models are useful in describing the action and interaction or inter relationship among various factors as well as for predicting the change in fertility behavior.

The stochastic models play an important role in estimation and interpretation of the fertility parameters. Birth interval is a good index for current change in fertility behavior.

In this paper, probability distribution model on straddling births has been derived for the estimation of fecundability based on assumptions of human reproductive process, indirectly incorporating socio, bio-demographic factors, 
taboos and use of contraceptive practices. The present model has been derived on the assumption that females are not exposed to the risk of conception immediately after the termination of Post-Partum Amenorrhea (PPA). However they may be exposed to the risk of conception at different point of time after the termination of PPA because of some socio-cultural factors or contraceptive practices. In this probability model for forward birth interval regardless of parity assuming that renewal density does not change over time and females are exposed to the risk of conception at different point of time.

\subsection{Some of the Main Biological Factors}

Fecundability: It is defined as the probability that a non pregnant fecund woman will conceive in one unit of the time of the exposure to the risk of conception. The unit is taken as one month which is the length of a menstrual cycle.

Sterility: A female is said to be sterile if conception is impossible physiologically.

Foetal Wastage: A conception may not always result in a live birth. The outcome of the corresponding pregnancy may end in a spontaneous foetal death, an induced abortion and still birth.

Non Susceptible Period: This is the sum of the two parts; first, gestation period and second the interval after its termination and before the resumption of the ovulation, which is the known as post partum amenorrhea (PPA) period.

There are two broad categories of the fertility model. First, the model which deals with the utilization of the data on point events like as conception, live births to women in a specified period of time. The second type of models utilizes the data on interval between the consecutive events. Both type of models have own usefulness as well as limitations. The present paper is associated with second type of model. Various type of birth intervals discussed so far in the literature are:

First Birth Interval: The interval between marriages to first live birth. This interval gives the recent marital fertility performance.

Closed Birth Interval: The interval between two successive live births. This gives the actual fertility performance in between two successive birth as well as impact of PPA and temporary separation and impact of family planning.

Open Birth Interval: The interval between the dates of birth of last child to the date of the survey. This provides the latest fertility performance.

Forward Birth Interval: The interval between survey date and the date of next live birth posterior to the survey date.

Straddling Birth Interval: Any closed birth interval that straddles the survey date.

\subsection{Review and Applications of Birth Interval}

The statistical models for complex fertility process play an important role in drawing inferences from the observed data and also providing the estimates of the fertility parameters relating to the human reproduction process. In the derived models so far, adequate attention has not been given to the prevalent socio-cultural and contraceptive practices. Needless to say that these factors are regulates and determine the coital pattern and abstinence after marriage or child birth. Moreover, they also affect fecundability and non susceptible periods. Thus, the present existing model may not be appropriate to describe the real fertility data. Gini (1924) was the first in this area to initiate research in model construction, by introducing the concept of fecundability [4]. Sheps (1964) and Singh (1966) and others have given detailed discussions on the variables to be included in the model $[5,6]$. In the last decades considerable attention has been given to analyze the data on closed birth interval or interval between two successive live births. The main importance of the closed birth interval is due to inclusion of amenorrhoiec period, temporary separation due to social taboos or use of contraceptives. Bhattacharya et al. (1988) have derived a probability model to describe the length of interval between successive live births by taking different parametric form of risk function and one to one correspondence between conception and a live birth [7]. Singh (1989) derived time dependent model for inter live birth interval with finite exposure period by taking into account intrauterine mortality and a distribution for the non- susceptible period [8]. Singh (1992) derived analytical models for human fertility behavior and their applications with the consideration of socio cultural and contraceptive factors [9]. Mturi (1997) studied the determinants of birth interval s among non contracepting Tanzanian women [10]. Rao (2006) studied correlates of inter-birth interval and their implications of optional birth spacing strategies in Mozambique [11]. Recently, Singh et al. (2011) discussed the demographic and socio-economic determinants of birth interval dynamics [12]. Yadav et al. (2013) estimate the parity progression ratios from open and closed birth interval data [13]. Singh (2014) derived the probability model on close birth interval and forward birth interval and estimated the fecundability [14-15]. The above derived and discussed analytical models associated with the birth intervals which terminated on or before the survey date. The data on straddling birth interval, defined as a closed birth interval that straddles the survey date, is easy to obtain more accurately, though the collection of data requires retrospective as well as prospective surveys. In other words, any closed birth interval that straddles the survey date. This type of interval is useful for the study of reproduction of subsequent fecund women of a particular age group initially proposed by Henry (1961). Sehgal (1971), while testing the sensitivity and robustness through simulation models of different types of birth intervals has shown that straddling birth interval is more sensitive to the change in the level of fertility[16-17]. Sheps et al. (1970) derived some general continuous distributions for straddling birth interval and compared with the distribution of usual closed birth interval [18]. Sehgal (1973) has derived expressions for the mean and variance of straddling birth interval in terms of preceding closed birth interval and open 
birth interval [19]. Pandey (1981) derived models for straddling birth interval for fixed parity and marital duration as well as regardless of parity by taking into account that all the females are susceptible for conception immediately after effective or return marriage and there is one to one correspondence between conception and live births[20]. Mishra (1983) extended probability model proposed by Pandey (1981) in view of the fact that different proportions of females are exposed to the risk of conception at different point of time and each conception does not result into live birth [21, 19]. Bhardwaj (1992) and Srivastava (1992) also derived models for birth interval on same pattern. In the above derived models, researcher assumed that all the females are exposed to the risk of conception just after termination of PPA [24-25]. However, all the females are may not expose to the risk of conception immediately after termination of PPA due to the some social factors and temporary family planning (use of contraceptive methods).

\subsection{Fundamental of Derived Probability Distribution Model}

Due to the socio cultural factors or contraceptive practices, some females not exposed to the risk of conception immediately after the termination of PPA. Probability model on successive live births has been derived for the estimation of fecundability based on assumptions of human reproductive process, indirectly incorporating socio, bio-demographic factors, taboos and use of contraceptive practices. In this model, fecundability $(\lambda)$ and the duration of time from the point of termination of PPA to the state of exposure as random variable $(\mu)$ which follows exponential distribution. The maximum likelihood estimation technique has been used for the estimation of parameters $\lambda$ and $\mu$ through derived model.

$\mathrm{T}$ units at a distant time point, after Return Marriage (R.M.) or effective marriage, a sample is drawn and observed until the next birth occurs and the intervals straddling the date of survey are obtained. Further, it is assumed that all the females survive until the delivery of the next live birth. In this paper derived the probability model of straddling birth interval to females of larger marital duration under the realistic assumptions given below.

1. The female has led married life throughout the period of observation.

2. Let $\mathrm{h}$ be the constant duration of non- susceptibility associated with each live birth comprised of gestation and the period of PPA.

3. The duration of non- susceptibility after the termination of PPA which is caused by some social factors or use of contraceptive practices be a non negative random variable. Let the female after termination of her PPA will enter into susceptible state in a small interval ( $t$, $\mathrm{t}+\Delta \mathrm{t})$ is $\mu \Delta \mathrm{t}+0 \Delta \mathrm{t} ; \mu>0, \Delta \mathrm{t}>0$ and $\mathrm{t}>0$

4. Let the female who is susceptible to conception at time $\mathrm{t}$ will conceive in a small interval $(\mathrm{t}, \mathrm{t}+\Delta \mathrm{t})$ is $\lambda \Delta \mathrm{t}+0 \Delta \mathrm{t}$; $\lambda>0, \Delta \mathrm{t}>0$ and $\mathrm{t}>0$

5. Let each conception results in to a live birth.
Let the female of marital duration $\mathrm{T}$ where $\mathrm{T}$ is distant time point since R.M. is observed. Then the probability density function of the straddling birth interval regardless of parity v (t) will be given according to Shep et al. 1970 and Cox 1965 [18, 26-27].

$$
v(t)=t f(t) / \mu^{*}
$$

where:

$f(t)=$ Probability density function of the waiting between two consecutive live births.

$$
\begin{aligned}
& \mathrm{f}(\mathrm{t})=\left[\mu \lambda /(\mu-\lambda)\left\{\mathrm{e}^{-\lambda(\mathrm{t}-\mathrm{h})}-\mathrm{e}^{-\mu(\mathrm{t}-\mathrm{h})}\right\}\right] \quad \text { Equation No. (1) } \\
& \mu^{*}=[\mathrm{h}+1 / \lambda+1 / \mu] \\
& v(t)=t[\mu \lambda /(\mu-\lambda)]\left[e^{-\lambda(t-h)}-e^{-\mu(t-h)}\right] /[h+1 / \lambda+1 / \mu] \text {; } \\
& \mathrm{t}>\mathrm{h} \quad \text { Equation No. }(2)
\end{aligned}
$$

and the corresponding distribution function,

$$
\begin{array}{r}
\mathrm{V}(\mathrm{t})=\left[\mathrm{h}+1 / \lambda+1 / \mu-1 /(\mu-\lambda)\left\{\mu(\mathrm{t}+1 / \lambda) \mathrm{e}^{-\lambda(\mathrm{t}-\mathrm{h})}-\lambda(\mathrm{t}+1 /\right.\right. \\
\left.\left.\mu) \mathrm{e}^{-\mu(\mathrm{t}-\mathrm{h})}\right\}\right] /[\mathrm{h}+1 / \lambda+1 / \mu] ; \mathrm{t}>\mathrm{h} \quad \text { Equation No. (3) }
\end{array}
$$

Consider the situation when the females are observed for a period, say $T_{1}$, starting from $T$. In this case all the females can not have a birth on or before the period of observation. Now, if we consider the straddling birth interval of those females who give their births during the period of observation $T_{1}$, the modified probability density function (p.d.f.) and corresponding distribution function will be,

$$
\begin{aligned}
& \mathrm{v}_{\mathrm{T} 1}^{*}(\mathrm{t})=\{\mathrm{t} \cdot \mathrm{f}(\mathrm{t})\} / \mathrm{F}^{*}\left(\mathrm{~T}_{1}\right) ; \mathrm{t} \leq \mathrm{T}_{1} \\
& =\left\{\mathrm{T}_{1} \cdot \mathrm{f}(\mathrm{t})\right\} / \mathrm{F}^{*}\left(\mathrm{~T}_{1}\right) ; \mathrm{t}>\mathrm{T}_{1} \quad \text { Equation No. }
\end{aligned}
$$

Where

$$
\begin{gathered}
\mathrm{F}^{*}\left(\mathrm{~T}_{1}\right)=\left[\mathrm{h}+1 / \lambda+1 / \mu-\left\{\mu \mathrm{e}^{-(\mathrm{T} 1-\mathrm{h})} / \lambda(\mu-\lambda)\right\}\right. \\
\left.+\left\{\lambda \mathrm{e}^{-(\mathrm{T} 1-\mathrm{h})} / \mu(\mu-\lambda)\right\}\right]
\end{gathered}
$$

On the substituions of the value of $F^{*}\left(T_{1}\right)$ and $f(t)$ in Equation No. 4

$$
\begin{gathered}
\mathrm{v}^{*} \mathrm{~T} 1(\mathrm{t})=\mathrm{t} .\left[\mu \lambda /(\mu-\lambda)\left\{\mathrm{e}^{-\lambda(\mathrm{t}-\mathrm{h})}-\mathrm{e}^{-\mu(\mathrm{t}-\mathrm{h})}\right\}\right] /\left[\mathrm{h}+1 / \lambda+1 / \mu-\left\{\mu \mathrm{e}^{-}\right.\right. \\
\left.(\mathrm{T} 1-\mathrm{h}) / \lambda(\mu-\lambda)\}+\left\{\lambda \mathrm{e}^{-(\mathrm{T} 1-\mathrm{h})} / \mu(\mu-\lambda)\right\}\right] ; \mathrm{h}<\mathrm{t} \leq \mathrm{T}_{1} \\
\mathrm{~T}_{1} \cdot\left[\mu \lambda /(\mu-\lambda)\left\{\mathrm{e}^{-\lambda(\mathrm{t}-\mathrm{h})}-\mathrm{e}^{-\mu(\mathrm{t}-\mathrm{h})}\right\}\right] /\left[\mathrm{h}+1 / \lambda+1 / \mu-\left\{\mu \mathrm{e}^{-(\mathrm{T} 1-\mathrm{h})} /\right.\right. \\
\left.\lambda(\mu-\lambda)\}+\left\{\lambda \mathrm{e}^{-(\mathrm{T} 1-\mathrm{h})} / \mu(\mu-\lambda)\right\}\right] ; \mathrm{t}>\mathrm{T}_{1}
\end{gathered}
$$

and the corresponding distribution function as

$$
\begin{gathered}
\mathrm{V}_{\mathrm{T} 1}^{*}(\mathrm{t})=\mathrm{H}_{11}(\mathrm{t}) / \mathrm{F}^{*}\left(\mathrm{~T}_{1}\right) ; \mathrm{h}<\mathrm{t} \leq \mathrm{T}_{1} \\
=\mathrm{H}_{12}(\mathrm{t}) / \mathrm{F}^{*}\left(\mathrm{~T}_{1}\right) ; \mathrm{t}>\mathrm{T}_{1}
\end{gathered}
$$

Where

$$
\begin{gathered}
\mathrm{H}_{11}=\left[\mathrm{h}+1 / \lambda+1 / \mu-1 /(\mu-\lambda)\left\{\mu(\mathrm{t}+1 / \lambda) \mathrm{e}^{-\lambda(\mathrm{t}-\mathrm{h})}-\lambda(\mathrm{t}+1 / \mu)\right.\right. \\
\left.\left.\mathrm{e}^{-\mu(\mathrm{t}-\mathrm{h})}\right\}\right] \\
\mathrm{H}_{12}=\left[\mathrm{h}+1 / \lambda+1 / \mu-\mu /(\mu-\lambda)\left\{1 / \lambda \mathrm{e}^{-\lambda(\mathrm{T} 1-\mathrm{h})}+\mathrm{T} . \mathrm{e}^{-\lambda(\mathrm{t}-\mathrm{h})}\right\}+\right. \\
\left\{\lambda /(\mu-\lambda)\left\{1 / \mu \mathrm{e}^{-\lambda(\mathrm{T} 1-\mathrm{h})}+\mathrm{T} \cdot \mathrm{e}^{-\lambda(\mathrm{t}-\mathrm{h})}\right\}\right.
\end{gathered}
$$


If it is assumed that $\mathrm{h}$ takes value $\mathrm{h}_{1}<\mathrm{h}_{2}<\ldots \ldots<\mathrm{h}_{\mathrm{q}}$ with respective proportions of females $b_{1}, b_{2}, \ldots \ldots \ldots, b_{q}$. The probability density function and probability distribution function of the derived model extend to,

$$
\begin{aligned}
& \mathrm{v}^{* *}{ }_{\mathrm{T} 1}=\sum \mathrm{b}_{\mathrm{v}} \mathrm{v}\left(\mathrm{t} / \mathrm{h}=\mathrm{h}_{\mathrm{v}}\right) ; \mathrm{v}=1,2, \ldots \ldots \mathrm{q} \\
& \mathrm{V}^{* *}{ }_{\mathrm{T} 1}=\sum \mathrm{b}_{\mathrm{v}} \mathrm{V}\left(\mathrm{t} / \mathrm{h}=\mathrm{h}_{\mathrm{v}}\right) ; \mathrm{v}=1,2, \ldots \ldots \mathrm{q}
\end{aligned}
$$

In the derived model, the parameter $\lambda$ and $\mu$ estimated through method of maximum likelihood (MLE) for observed distribution of PPA and other parameters to be estimated from the observed data.

\subsection{Application of Derived Model}

The application of the derived model on real observed data taken from Demographic Survey of Varanasi Rural, India. As a close approximation in the estimates for the present surveyed population we have taken four point observed values of PPA eq. 3 months, 6 months, 12 months and 18 months with respective proportion of females $b_{1}=0.25$, $\mathrm{b}_{2}=0.35, \mathrm{~b}_{3}=0.32$ and $\mathrm{b}_{4}=0.08$, such that $\sum \mathrm{b}_{\mathrm{v}}=1$. Further, gestation period $\mathrm{g}$ is taken as 9 months $\left(\mathrm{h}_{1}=1.00, \mathrm{~h}_{2}=1.25\right.$, $h_{3}=1.75$, and $h_{4}=2.25$ ). The remaining two parameters of the model $\lambda$ and $\mu$ are estimated through Maximum Likelihood Estimates [9].

\section{Results}

The estimated values of $\lambda$ and $\mu$ are 1.0551 and 5.75 respectively (Table 1 ). The variance of estimated $\lambda$ and $\mu$ are 0.0017 and 0.3027 respectively. The co-variance in between estimated values of $\lambda$ and $\mu$ is -0.0142 . With these estimates the expected frequencies for the distribution and $\chi^{2}=1.0230$ is significant at $5 \%$ level of significance (Table $2)$. The estimate of $\lambda \& \mu$ (1.0551 and 5.75) is almost same as compared to the estimates obtained from the data on open birth interval [9]. These above mentioned estimates have considered and based on the rate of entrance into the state of exposure after the termination of PPA. With these estimates of $\lambda$ and $\mu$ as well as variance and on the basis of expected frequencies for the distribution $\left(\chi^{2}=1.0230\right)$ is significant. Thus, the derived probability model explains the fertility behavior of observed data satisfactorily well. Therefore, conclude that the derived model describes the real situations and provides the better estimates of human fertility behavior.

Table 1. Estimated value of parameters and their corresponding variances and co-variance.

\begin{tabular}{ll}
\hline Parameters & Estimated Value \\
\hline$\lambda$ & 1.0558 \\
$\mu$ & 5.7511 \\
$V(\lambda)$ & 0.0017 \\
$V(\mu)$ & 0.3027 \\
$\operatorname{Cov}(\lambda, \mu)$ & -0.0142 \\
\hline
\end{tabular}

Table 2. Distribution of observed and expected frequencies of straddling birth interval.

\begin{tabular}{lll}
\hline Time in Years & Observed Frequencies & Expected Frequencies \\
\hline $0.75-1.75$ & 12 & 12.05 \\
$1.50-2.00$ & 44 & 42.14 \\
$2.00-2.50$ & 65 & 62.15 \\
$2.50-3.00$ & 54 & 52.98 \\
$3.00-3.50$ & 35 & 35.10 \\
$3.50-4.00$ & 17 & 20.75 \\
4.00 and above & 28 & 29.83 \\
Total & 255 & 255.00 \\
D.F. & 4 & \\
$\chi^{2}$ & 1.0230 & \\
\hline
\end{tabular}

\section{Summary and Conclusion}

Human fertility behavior is responsible for population growth and it is also for infant mortality. These factors are highly responsible for development of nation and puts extra pressure on economy of nation. Cognizant of these inherent problems, researcher, scientist and demographers have given high priority to a thorough understanding of the differential and determinants of fertility through mathematical and statistical methodologies.

The estimate of $\lambda$ obtained by Mishra, 1983 were quite low as compared to estimates of Western countries probably due to the various social and cultural factors affecting human fertility in the rural parts of India viz., the frequent visits to females to their parents in their early marital life, practices of prolonged lactation, joint family system and various other social taboos [21]. The estimate of $\lambda$ is quite high compared to estimates obtained previous estimate $\lambda=0.79$ and in another research study $\lambda=0.78$ [21-23]. The previous studies as mentioned above have not considered the rate of entrance into the state of exposure after the termination of PPA. The high estimate of $\lambda$ is may be due to improvement in the standard of living and also as an impact of urbanization. Further, with passage of time probably role of social customs and rituals has declined in three decades.

The present described model and results relates to some factors of human reproduction and compared with another estimates obtained through analytical birth interval models which take account of a few factors. It is difficult to cover all the associated factors of human fertility behavior. However, the present derived model can explain and gives the better understanding of change in complex human fertility behavior. Derived model also helps to assessing the real impact of family planning programmes and their effectiveness. Srivastava (1989), Bhardwaj (1989) reported same pattern of fecundibility [24-25]. Singh (2014) reported same trend of fecundability and females are expose to the risk of conception at different point through stochastic model of fecundability in between two successive live births (Closed Birth Interval) and also through forward birth interval and stated that almost all females are exposed to the risk of conception within a year after termination of PPA [14-15]. Thus, the derived probability model explains the fertility 
behavior of observed data satisfactorily well and derived model will also help to the researcher for unbiased estimation of risk of conception. Therefore, derived model is explained the human fertility behavior in better manner and provides the estimate of the parameters with insignificant variance.

\section{Acknowledgement}

Words fail to me express my deep sense of gratitude to my venerable preceptor Prof. R. N. Mishra, Division of Biostatistics, Department of Community Medicine, Institute of Medical Sciences, BHU, India. I owe special debt of gratitude to Prof. M. B. Masuku, Department of AEM, University of Swaziland, Swaziland, for his valuable suggestions. Lastly, thanks to my family members for their affectionate help and moral support.

\section{References}

[1] Freedman, R., "Expected family size and family size value in West Germany", Population Studies, 13; 136, 159.

[2] Lenski, G., "The religious factor, Anchor Books", Doubleday, New York, USA, 1963.

[3] Goldberg, D., "Some observations on recent changes in American fertility based on sample survey data", Eugenics Quarterly, 14(4), 255, 1967.

[4] Gini, C., "Premieres researches sur la fecundabilite de la femme", Proceedings of the International Mathematics Congress, Toronto, 889-892, 1924.

[5] Sheps, M. C., "Pregnancy wastage as a factor in the analysis of fertility data", Demography, 1, 111-118, 1964.

[6] Singh, S. N., "Some probability distributions utilized in human fertility", Seminar volume in statistics, BHU, Varanasi, India, p.74, 1966.

[7] Bhattacharya, B.N., C. M. Pandey and K. K. Singh, "Model for closed birth interval and some social factors", Janasankhya, $6(1) ; 57,1988$.

[8] Singh, U., "Fertility analysis through birth interval models", unpublished Ph.D. Thesis, Banaras Hindu University, Varanasi, India, 1988.

[9] Singh, A.S., "Some analytical models for human fertility and their applications", unpublished Ph.D. Thesis, Institute of Medical Sciences, BHU, Varanasi, India, 1992.

[10] Mturi, A. J., "The determinants of birth intervals among non contracepting Tanzanin women", African Population Studies, 12(2), 1997.

[11] Rama Rao S., T. John and A. Ian, "Correlates of inter birth intervals: Implications of optional birth spacing strategies in Mozambique", Population Council, 1-17, 2006.
[12] Singh S. N., S. N. Singh and R. K. Narendra, "Demographic and socio-economic determinants of birth interval dynamics in Manipur : A survival analysis", Online Journal of Health and Allied Sciences, 9(4), 2011.

[13] Yadav R.C., A. Kumar A. and M. Pratap,"Estimation of parity progression ratios from open and closed birth interval, Journal of Data Science, 11, 607-621, 2013.

[14] Singh, A. S., "Stochastic model for estimation of fecundability in between two successive live births (Closed Birth Interval)", Presented in 3 International Science Congress, India, Published in Recent Jr. Research Sciences, 3 (ISC-2013), 1-3, 2014.

[15] Singh Ajay Shankar, "Probability model for forward birth interval and its application, American Jr. of Theoretical and Applied Statistics, 3(6), 223-227, 2014.

[16] Henry L.,Fecondite at famille models mathematiques, Population, 16, 261. 1961.

[17] Sehgal, J.M., "Indices of fertility derived from data on the length of birth intervals, using different ascertainment plans" Thesis from Department of Biostatistics, University of North Carolina, Institute of Statistics Memo Series, 768, 1971.

[18] Sheps, M.C., Menken, J.A., Ridley, J.C. and Lingner, J.W. (1970): Truncation effect in closed birth interval and open birth interval data, Journal of American Statistical Association, 65:678.

[19] Sehgal, J.M., "On straddling birth intervals, Demography India, $2 ; 212,1973$

[20] Pandey, A., A study of some probability models for birth intervals, Ph. D. Thesis, Banaras Hindu University, India, 1981.

[21] Mishra, R. N., "Some stochastic models and their utility to describe birth interval data", Ph. D. Thesis, Banaras Hindu University, India, 1983.

[22] Singh, S. N., R. C. Yadav and A. Pandey, "On a generalized distribution of open birth interval regardless of parity, Journal of Scientific Research, BHU, India, (1979).

[23] Singh, S. N., A. Pandey and R. N. Mishra, "A generalized probability distribution for open birth interval, The Aligarh Journal of Statistics, 1 (2), p. 183, 1981.

[24] Bhardwaj, S. D., Ph. D. (Statistics-Preventive and Social Medicine) unpublished thesis, Institute of Medical Sciences, Thesis, Banaras Hindu University, India, 1992.

[25] Srivastava, P. K., Ph. D. (Statistics-Preventive and Social Medicine) unpublished thesis, Institute of Medical Sciences, Banaras Hindu University, India, 1992.

[26] Cox, D. R. and H. D. Miller, "The theory of stochastic process', Methuen Co. Ltd., London, UK, 1965.

[27] Yadava R.C. and A Pandey, "Probability models for the study of straddling birth intervals", Biometrical Journal, Wiley Online Library, 1989. 